\title{
First and second eye cataract surgery and driver self-regulation among older drivers with bilateral cataract: a prospective cohort study
}

\author{
Seraina Agramunt ${ }^{1}$, Lynn B. Meuleners ${ }^{1 *}$, Michelle L. Fraser ${ }^{1}$, Kyle C. Chow ${ }^{1}$, Jonathon Q. Ng ${ }^{2,3}$ and Vignesh Raja ${ }^{4}$
}

\begin{abstract}
Background: Driving a car is the most common form of transport among the older population. Common medical conditions such as cataract, increase with age and impact on the ability to drive. To compensate for visual decline, some cataract patients may self-regulate their driving while waiting for cataract surgery. However, little is known about the self-regulation practices of older drivers throughout the cataract surgery process. The aim of this study is to assess the impact of first and second eye cataract surgery on driver self-regulation practices, and to determine which objective measures of vision are associated with driver self-regulation.

Methods: Fifty-five older drivers with bilateral cataract aged 55+ years were assessed using the self-reported Driving Habits Questionnaire, the Mini-Mental State Examination and three objective visual measures in the month before cataract surgery, at least one to three months after first eye cataract surgery and at least one month after second eye cataract surgery. Participants' natural driving behaviour in four driving situations was also examined for one week using an in-vehicle monitoring device. Two separate Generalised Estimating Equation logistic models were undertaken to assess the impact of first and second eye cataract surgery on driver-self-regulation status and which changes in visual measures were associated with driver self-regulation status.
\end{abstract}

Results: The odds of being a self-regulator in at least one driving situation significantly decreased by $70 \%$ after first eye cataract surgery (OR: $0.3,95 \% \mathrm{Cl}: 0.1-0.7)$ and by $90 \%$ after second eye surgery (OR: $0.1,95 \%$ Cl: $0.1-0.4$ ), compared to before first eye surgery. Improvement in contrast sensitivity after cataract surgery was significantly associated with decreased odds of self-regulation (OR: 0.02, 95\% Cl: 0.01-0.4).

Conclusions: The findings provide a strong rationale for providing timely first and second eye cataract surgery for older drivers with bilateral cataract, in order to improve their mobility and independence.

Keywords: Older drivers, Bilateral cataract, Cataract surgery, Self-regulation, Contrast sensitivity

\section{Background}

Globally, driving a car is the most common form of transport among the older population in developed countries $[1,2]$ and plays an important role in their lifestyle [3]. Driving cessation has been associated with poorer physical, social and cognitive function as well as depression [4]. As adults are living longer and healthier lives

\footnotetext{
* Correspondence: L.Meuleners@curtin.edu.au

${ }^{1}$ Curtin-Monash Accident Research Centre (C-MARC), Curtin University, GPO BOX U1987, PERTH, WA 6845, Australia

Full list of author information is available at the end of the article
}

[5] the number of older drivers on the roads will increase, which will have a significant impact on road safety [6].

Cataract is a common medical condition which increases with age and impacts on the ability to drive, increasing crash risk as well as driving difficulties [7-9]. To compensate for visual decline, previous research has found that some patients with cataract may self-regulate their driving while waiting for cataract surgery $[10,11]$. Self-regulation refers to an older driver adjusting their driving in response to a perceived deterioration in their health, cognitive or functional abilities [12] which may result in a reduction 
in their driving or avoidance of specific driving situations $[12,13]$.

Surgery is a highly effective treatment for cataract. However bilateral cataract surgery is usually performed one eye at a time to avoid complications, such as endophthalmitis [14]. This means patients may be driving during the period between first and second eye surgery. To date, there is limited information about the impact of cataract surgery on driver self-regulation practices, specifically the separate effects of first and second eye surgery for bilateral cataract patients. While it is likely that first eye cataract surgery reduces the need for driver self-regulation it is unknown whether second eye surgery provides any additional benefits. As well, previous research has suggested that poor contrast sensitivity is strongly associated with driver self-regulation among the general older population [15-19]. It would therefore be useful to determine whether improvement in contrast sensitivity or other visual measures after first and second eye cataract surgery is associated with a reduction in driver self-regulation.

Naturalistic driving studies using in-vehicle monitoring devices can provide objective and accurate measures of driver self-regulation practices [20] and are able to capture participants' real-life driving behaviour. A growing body of evidence comparing self-reported driving behaviour and naturalistic driving data has found that older drivers often misjudge their kilometres travelled, days driven per week as well as frequency of driving in challenging situations such as at night, in bad weather, in peak hour traffic and on highways $[20,21]$. Therefore it is recommended that these devices be used to monitor driving outcomes rather than self-reported questionnaires alone [22]. To date, no study has used naturalistic driving data to examine changes in driver self-regulation behaviour throughout the cataract surgery process.

Therefore, the aim of this study is to assess the separate impact of first and second eye cataract surgery on driver self-regulation status, for bilateral cataract patients. A secondary aim of the study is to determine which changes in objective measures of vision are associated with changes in driver self-regulation status throughout the cataract surgery process.

\section{Methods}

\section{Study design}

A longitudinal prospective cohort study of older drivers with bilateral cataract was undertaken as part of the larger Cataract Extraction Driving Ability Research Study (CEDAR Study) [23]. A convenience sample of eligible participants were recruited consecutively from three public hospitals in Western Australia through two methods: direct invitation from ophthalmologists during their visit to the eye clinic or invitation letter from the researchers. From 290 eligible patients invited to take part in the study, 111 participated (38\%) and 55 of these completed all three assessments.

\section{Eligibility criteria}

The inclusion criteria were: a diagnosis of bilateral cataract; aged 55+ years; a current Western Australian driver's licence; and driving at least twice a week. Exclusion criteria for participants were: a diagnosis of any significant eye conditions such as macular degeneration, glaucoma or diabetic retinopathy; a diagnosis of dementia, Alzheimer's or Parkinson's disease; wheelchair-bound; did not speak English or had previous cataract surgery.

\section{Data collection}

Eligible participants were recruited between December 2014 and February 2017. Information was collected at three-time points for the participants: in the month before first eye surgery, at least one to three months after first eye surgery and at least one month after second eye surgery. Participants received a Participant Information Sheet and provided written informed consent before any data were collected, following the tenets of the Declaration of Helsinki. Ethics approval was obtained from the Curtin University Human Research Ethics Committee (Curtin University HR 29/2014), the Royal Perth Hospital Human Research Ethics Committee (Royal Perth \#14-033), the South Metropolitan Health Service Human Research Ethics Committee (Fremantle Hospital \#14-033), and the Sir Charles Gairdner Group Human Research Ethics Committee (Sir Charles Gairdner Hospital \#2014-113).

\section{Questionnaires}

Participants' demographic characteristics were collected. As well, the Driving Habits Questionnaire (DHQ) [10] collected information on participants' self-reported driving patterns, exposure and self-regulation practices in eight driving situations at the three assessments. The DHQ has been previously validated for use among a population of older drivers with bilateral cataract in Western Australia [24].

\section{Mini-mental state examination (MMSE)}

General cognitive function was assessed using the MiniMental State Examination (MMSE) at the three assessments [25]. The inclusion criterion stipulated a score of at least 24 indicating normal cognitive function.

\section{Objective visual measures}

Visual acuity, contrast sensitivity and stereopsis were assessed at the three time points by the researcher under the guidance of an ophthalmologist. A standardised protocol was followed under constant conditions and luminance. Participants wore their habitual corrective lenses or glasses used for driving for visual testing. Monocular and binocular 
visual acuity were measured at a distance of three metres using an Early Treatment Diabetic Retinopathy Study (ETDRS) acuity chart [26]. Letter by letter scoring was used and scores were converted to the logarithm of the minimum angle resolution (logMAR). Monocular and binocular contrast sensitivity were measured at $50 \mathrm{~cm}$ using the Mars Letter Contrast Sensitivity Test [27]. Scores were expressed as log units and participants were encouraged to guess the letters if hesitating, as directed by the protocol. Stereopsis was measured using the Titmus Fly Stereotest (Good-Lite Co., Inc.), measuring disparity from 4800 to $20 \mathrm{~s}$ of arc.

\section{In-vehicle monitoring device}

A Geotab G06 $^{\mathrm{TM}}$ in-vehicle monitoring device with GPS log receiver was provided to the participants at the three assessments to record their naturalistic driving patterns for a period of seven days. The devices were connected either to the cigarette lighter for vehicles manufactured before 2006 or the On Board Diagnostic II (OBD II) port for vehicles manufactured after January 2006. The device can be easily inserted and removed and this was demonstrated to the participants. They were asked to disconnect the device if someone else drove the vehicle and move the device to any other vehicle they drove during the study period. Participants were also provided with a travel diary which was used to validate whether the participant was the driver of the vehicle for each trip. They were instructed to fill in the diary as soon as possible after the completion of each trip so their recall was accurate. Information collected included the type of vehicle driven, the number, age and position of passengers, purpose of the trip, date, start and finish time, odometer readings, trip duration and distance travelled. If they were unable to or forgot to disconnect the device when another person drove the vehicle, they were also asked to record this in the travel diary. After returning the device, each participant was interviewed to clarify any data issues, check their use of multiple vehicles and confirm whether there had been any other drivers of the vehicle while the device was connected.

The objective data obtained from the in-vehicle monitoring device included driving exposure, time and date of travel, speed, type of road and location. Night time driving was defined as the period between sunset and sunrise as obtained from the Australian Government Bureau of Meteorology website [28]; peak hour driving was from six to nine am and/or four to seven pm from Monday to Friday. Roads where there were more than 4000 vehicles per day per lane were defined as "heavy traffic roads" [29]. This information was obtained from Main Roads WA which is the State Government agency responsible for the road network in WA. To determine whether participants drove on highways/freeways, the researcher examined an interactive map provided by Geotab@ which detailed each trip made by the participant.

\section{Classification criteria for driver self-regulation practices}

Four driving situations were obtained from the selfreported DHQ which could be directly compared to the information obtained from the in-vehicle monitoring device. These four situations were used to classify participants as either self-regulating or non-self-regulating their driving in each situation. These situations included "driving on highways/freeways", "on heavy traffic roads", "in peak hour traffic" and "night time driving". Initially, each of the four driving situations were examined separately to determine if participants' self-regulated their driving in that situation. For example, participants were considered to have self-regulated their driving if they responded that they had not driven at night time based on information from the DHQ and the data from the in-vehicle monitoring device confirmed the same behaviour. Then all four driving situations were examined together and participants were classified as a "self-regulator" if they self-regulated their driving behaviour in at least one of the four driving situations. Otherwise, they were considered to be a "non selfregulator".

\section{Statistical analysis}

Descriptive statistics were used to describe the characteristics of the cohort. Repeated measures of analysis of variance (ANOVA) were used to assess the changes in the objective measures of vision. Cochran's Q Tests were used to analyse the changes in driver self-regulation status in the four driving situations.

The outcome of interest was driver self-regulation status (self-regulator/non self-regulator). Two separate Generalised Estimating Equation (GEE) logistic models were undertaken. The GEE method is suitable for longitudinal or repeated measures study designs where observations within each participant are not independent [30]. GEEs permit specification of a certain working correlation matrix that accounts for this within-subject correlation, thus providing more robust regression coefficients. The first GEE logistic model analysed whether there was a significant change in self-regulation status after first and second eye cataract surgery, while controlling for potential confounding factors. The visual measures were not included in this model because vision changed as a result of the surgery.

The second model was undertaken to examine which changes in the three visual measures were associated with changes in driver self-regulation status. Potential confounding factors such as cognitive status (MMSE score), age group (55-64/ 65-74/ 75+ years), gender (female/male), marital status (single/married or de facto), retirement status (not retired/retired), and the number of comorbidities 
were entered in both models. All statistical analyses were performed using STATA $15^{\circ}$.

\section{Results}

Fifty-five participants completed all three assessments resulting in 165 observations. Table 1 presents the baseline demographic characteristics of the cohort before first eye cataract surgery. Participants' mean age was 73.3 years (SD $=7.8$ ) with $43.6 \%$ aged 75 years or older. The majority of participants were female (54.5\%), married or in a defacto relationship (61.8\%), had completed a higher education degree (58.2\%), lived with another person (54.5\%) and were retired $(76.4 \%)$. The mean score of $27.6(\mathrm{SD}=2.2)$ on the MMSE indicated normal cognitive function. Participants also reported an average of 5.3 medical conditions $(\mathrm{SD}=2.5)$ and an average of 50.9 years $(\mathrm{SD}=9.5)$ driving experience at baseline.

Participants' visual characteristics are presented in Table 2.

Table 1 Baseline demographic characteristics of older drivers with bilateral cataract $(n=55)$

\begin{tabular}{|c|c|}
\hline Variable & n (\%) \\
\hline Age: mean (SD) & $73.3(7.8)$ \\
\hline \multicolumn{2}{|l|}{ Age group (years) } \\
\hline $55-64$ & $10(18.2 \%)$ \\
\hline $65-74$ & $21(38.2 \%)$ \\
\hline $75+$ & $24(43.6 \%)$ \\
\hline \multicolumn{2}{|l|}{ Country of birth } \\
\hline Australia & $21(38.2 \%)$ \\
\hline Not Australia & $34(61.8 \%)$ \\
\hline \multicolumn{2}{|l|}{ Gender } \\
\hline Female & $30(54.5 \%)$ \\
\hline Male & $25(45.5 \%)$ \\
\hline \multicolumn{2}{|l|}{ Marital status } \\
\hline Single/separated/divorced/widowed & $21(38.2 \%)$ \\
\hline De facto/married & $34(61.8 \%)$ \\
\hline \multicolumn{2}{|l|}{ Retirement status } \\
\hline Not retired & $13(23.6 \%)$ \\
\hline Retired & $42(76.4 \%)$ \\
\hline \multicolumn{2}{|l|}{ Living arrangements } \\
\hline Alone & $25(45.5 \%)$ \\
\hline Not alone & $30(54.5 \%)$ \\
\hline \multicolumn{2}{|l|}{ Level of education } \\
\hline Primary or Secondary School & $23(41.8 \%)$ \\
\hline Higher Education & $32(58.2 \%)$ \\
\hline Driving experience (years): mean (SD) & $50.9(9.5)$ \\
\hline Number of comorbidities: mean (SD) & $5.3(2.5)$ \\
\hline MMSE score: mean (SD) & $27.6(2.2)$ \\
\hline
\end{tabular}

MMSE Mini-Mental State Examination, SD standard deviation
Table 2 Mean visual characteristics of older drivers before, after first and after second eye cataract surgery $(n=55)$

\begin{tabular}{|c|c|c|c|c|}
\hline Variable & $\begin{array}{l}\text { Before surgery } \\
\text { Mean (SD) }\end{array}$ & $\begin{array}{l}\text { After first } \\
\text { eye surgery } \\
\text { Mean (SD) }\end{array}$ & $\begin{array}{l}\text { After second } \\
\text { eye surgery } \\
\text { Mean (SD) }\end{array}$ & $P$ value \\
\hline \multicolumn{5}{|c|}{$\overline{\text { Visual acuity }(\log M A R)^{a}}$} \\
\hline Better eye & $0.18(0.15)$ & $0.10(0.22)$ & $0.00(0.19)$ & $<0.001$ \\
\hline Worse eye & $0.39(0.24)$ & $0.36(0.26)$ & $0.11(0.19)$ & $<0.001$ \\
\hline Binocular & $0.15(0.15)$ & $0.08(0.21)$ & $-0.02(0.19)$ & $<0.001$ \\
\hline \multicolumn{5}{|c|}{ Log contrast sensitivity (log units) ${ }^{b}$} \\
\hline Better eye & $1.57(0.14)$ & $1.62(0.28)$ & $1.68(0.11)$ & $<0.001$ \\
\hline Worse eye & $1.41(0.29)$ & $1.47(0.27)$ & $1.61(0.13)$ & $<0.001$ \\
\hline Binocular & $1.64(0.14)$ & $1.67(0.25)$ & $1.75(0.08)$ & $<0.001$ \\
\hline \multicolumn{5}{|c|}{ Stereopsis (log seconds of arc) ${ }^{a}$} \\
\hline Binocular & $2.14(0.64)$ & $2.31(0.72)$ & $1.96(0.60)$ & 0.002 \\
\hline
\end{tabular}

${ }^{a}$ Lower scores represent better vision ${ }^{\mathrm{b}} \mathrm{Higher}$ scores represent better vision $\log$ logarithm, logMAR logarithm of the Minimal Angle of Resolution, SD standard deviation

Mean binocular visual acuity significantly improved from $0.15 \log$ MAR $(S D=0.15)$ at baseline, to $0.08 \log M A R$ $(\mathrm{SD}=0.21)$ after first eye surgery and $-0.02 \log \mathrm{MAR}$ $(\mathrm{SD}=0.19)$ after second eye surgery $(p<0.001)$.

Binocular contrast sensitivity significantly improved $(p<0.001)$ from 1.64 log units $(\mathrm{SD}=0.14)$ before first eye cataract surgery, to $1.67 \log$ units $(\mathrm{SD}=0.25)$ after first eye cataract surgery and $1.75 \log$ units $(\mathrm{SD}=0.08)$ after second eye cataract surgery.

A significant change $(p=0.002)$ in stereopsis was found with stereopsis measuring $2.14 \log$ seconds of arc $(\mathrm{SD}=$ 0.64 ) at baseline; worsening to $2.31 \mathrm{log}$ seconds of arc $(\mathrm{SD}=0.72)$ after first eye cataract surgery and improving to $1.96 \mathrm{log}$ seconds of arc $(\mathrm{SD}=0.60)$ after second eye surgery.

\section{Situations in which drivers self-regulated}

Before first eye surgery, $47.3 \%$ of participants were classified as self-regulators in at least one driving situation. This reduced to $29.1 \%$ after first eye surgery and $18.2 \%$ after second eye surgery. In terms of the specific driving situations avoided, before first eye surgery, $12.5 \%$ of participants did not drive on heavy traffic roads, while only $8.3 \%$ and $2.1 \%$ did not drive in this situation after first and second eye cataract surgery respectively, representing a significant change $(p=0.020)$. Before first eye surgery, $37.0 \%$ of participants did not drive at night which decreased to $21.7 \%$ after first and $10.9 \%$ after second eye cataract surgery, which was significant $(p=0.002)$. There was no significant change in driver self-regulation status for driving during peak hour traffic $(p=0.100)$ and freeway/highway driving $(p=0.900)$. 


\section{Multivariate analysis}

The results of the logistic Generalised Estimating Equation (GEE) model examining changes in self-regulation status after first and second eye cataract surgery are presented in Table 3. The odds of being a self-regulator in at least one driving situation significantly decreased by $70 \%$ after first eye cataract surgery (OR: $0.3,95 \%$ CI: $0.1-0.7$ ) and by $90 \%$ after second eye surgery (OR: 0.1, 95\% CI: 0.1-0.4), compared to before first eye cataract surgery, after adjusting for potential confounders. In addition, retired participants had 5.6 times the odds of selfregulating, compared to those who were employed (OR: 5.6, 95\% CI: 1.1-27.7).

The results of the logistic Generalised Estimating Equation (GEE) model examining changes in the three objective measures of vision and driver self-regulation status are presented in Table 4. Improvement in contrast sensitivity after cataract surgery was significantly associated with decreased odds of self-regulating (OR: 0.02, 95\% CI: 0.01-0.4). Males had significantly lower odds of being self-regulators (OR: 0.2: 95\% CI: 0.04-1.0) and retired participants had significantly higher odds of being self-regulators (OR: 10.1, 95\% CI: 1.8-54.8).

Table 3 GEE Logistic Model of the impact of first and second eye cataract surgery on self-regulation status

\begin{tabular}{|c|c|c|c|}
\hline Variable & Odds Ratio & $95 \% \mathrm{Cl}$ & $P$ value \\
\hline \multicolumn{4}{|l|}{ Cataract surgery } \\
\hline Before first eye surgery & 1.0 & & \\
\hline After first eye surgery & 0.3 & $0.1-0.7$ & 0.004 \\
\hline After second eye surgery & 0.1 & $0.1-0.4$ & $<0.001$ \\
\hline \multicolumn{4}{|l|}{ Gender } \\
\hline Female & 1.0 & & \\
\hline Male & 0.4 & $0.1-1.3$ & 0.122 \\
\hline \multicolumn{4}{|l|}{ Age group (years) } \\
\hline $55-64$ & 1.0 & & \\
\hline $65-74$ & 0.1 & $0.1-1.2$ & 0.072 \\
\hline $75+$ & 0.7 & $0.6-8.0$ & 0.737 \\
\hline \multicolumn{4}{|l|}{ Marital status } \\
\hline Single & 1.0 & & \\
\hline Married/de facto & 0.3 & $0.1-1.2$ & 0.096 \\
\hline \multicolumn{4}{|l|}{ Retirement status } \\
\hline Not retired & 1.0 & & \\
\hline Retired & 5.6 & $1.1-27.7$ & 0.036 \\
\hline Number of comorbidities & 1.1 & $0.9-1.4$ & 0.257 \\
\hline MMSE score & 1.0 & $0.9-1.2$ & 0.803 \\
\hline
\end{tabular}

Cl confidence interval, GEE Generalised Estimating Equation, log logarithm, logMAR logarithm of the Minimal Angle of Resolution, MMSE Mini-Mental State Examination, $S D$ standard deviation
Table 4 GEE Logistic Model of change in visual measures and self-regulation status among older drivers with bilateral cataract

\begin{tabular}{llll}
\hline Variable & Odds Ratio & $95 \% \mathrm{Cl}$ & $P$ value \\
\hline Gender & & & \\
$\quad$ Female & 1.0 & & \\
$\quad$ Male & 0.2 & $0.04-1.0$ & 0.045 \\
Age group (years) & & & \\
$\quad 55-64$ & 1.0 & & \\
$65-74$ & 0.1 & $0.1-1.4$ & 0.091 \\
$75+$ & 0.6 & $0.1-6.7$ & 0.125 \\
Marital status & & & \\
$\quad$ Single & 1.0 & & \\
$\quad$ Married/de facto & 0.6 & $0.2-2.6$ & 0.523 \\
Retirement status & & & \\
$\quad$ Not retired & 1.0 & & \\
$\quad$ Retired & 10.1 & $1.8-54.8$ & 0.008 \\
Number of comorbidities & 1.2 & $0.9-1.5$ & 0.174 \\
MMSE score & 1.0 & $0.8-1.3$ & 0.882 \\
Binocular visual acuity (logMAR) & 2.5 & $0.2-26.9$ & 0.455 \\
Binocular contrast sensitivity (log units) & 0.02 & $0.01-0.4$ & 0.019 \\
Stereopsis (log seconds of arc) & 1.3 & $0.5-3.5$ & 0.648 \\
\hline Cl confidence interval, GEE Generalised Estimating Equation, log logarithm, \\
logMAR logarithm of the Minimal Angle of Resolution, MMSE Mini-Mental State \\
Examination, SD standard deviation & & & \\
& & &
\end{tabular}

\section{Discussion}

This is one of the first studies to use naturalistic driving information to assess the impact of first and second eye cataract surgery on driver self-regulation practices among a cohort of older drivers with bilateral cataract. We found a significant reduction in driver self-regulation in at least one situation after both first and second eye cataract surgery, compared to the month before first eye cataract surgery. The study also found that changes in contrast sensitivity were associated with the reduction in driver self-regulation after cataract surgery.

The results of our study are consistent with some of the limited existing research on the impact of cataract surgery on driver self-regulation. A population-based study from Sweden found that $40 \%$ of all drivers increased their driving frequency after first eye or bilateral cataract surgery [31]. In addition, this study and a more recent prospective study from Sweden reported that between 25\% and 37\% of all patients who ceased driving before first eye cataract surgery started to drive after first eye or bilateral surgery $[31,32]$. However, an earlier study from the USA which followed cataract patients over a longer time period found that driving exposure (mileage) decreased over time in a similar fashion for those who had cataract surgery and those who did not [33]. It is therefore possible that decreased self-regulation observed in our study was perhaps a "rebound" effect with increased driving and less self- 
regulation occurring in the period immediately following surgery. Our study was unable to address the longer term impact of cataract surgery on driver self-regulation and this warrants further research.

Since previous studies combined participants who underwent only first, or both eye surgeries in the analyses, they were unable to measure the specific effects of first and second eye cataract surgery separately. Our study demonstrated that while first eye surgery had a large impact on reducing the need for driver self-regulation among bilateral cataract patients, second eye surgery also had a significant impact, reducing the odds of driver selfregulation by a further $20 \%$ compared to baseline. This suggests the importance of timely second eye cataract surgery for bilateral cataract patients.

Previous research also supports our findings on the association between contrast sensitivity and driving outcomes. Contrast sensitivity has been associated with changes in driving difficulty after first eye [24] and after second eye cataract surgery [34]. Among the general population, contrast sensitivity has also been associated with driver self-regulation and cessation $[15,16,18,19]$ as well as crash risk [35]. It should be noted that our cohort had better baseline vision, including contrast sensitivity than in previous studies examining the impact of cataract or cataract surgery on driving difficulty and self-regulation $[10,11,36,37]$. Despite this, $47.3 \%$ of participants still felt the need to self-regulate their driving due to their vision while waiting for first eye surgery, representing a significant limitation for their mobility. In addition, the relatively small improvement in binocular contrast sensitivity from baseline to after second eye surgery was still associated with a significant reduction in driver self-regulation. Although driver self-regulation is necessary and positive for road safety, it nevertheless limits an older person's mobility and independence in the community. It is well known that driving cessation can have a negative impact on their lifestyle [3], but evidence suggests that self-regulation without cessation may also increase depressive symptoms among the general older population [38] and cataract patients specifically [11]. Therefore, our findings suggest that first and second eye cataract surgery can have a significant positive impact on restoring the mobility of drivers with bilateral cataract, even if their visual impairment is relatively mild.

The study also found that both first and second eye cataract surgery significantly reduced driver self-regulation in two specific situations; driving at night and on heavy traffic roads. A previous study also found that night time driving was the most common situation avoided by older drivers awaiting first eye cataract surgery [11]. Previous research also reported that $36 \%$ of older drivers with cataract had difficulty driving on heavy traffic roads [10]. However, neither of these studies examined how self-regulation status changed throughout the cataract surgery process and relied on the DHQ questionnaire alone to assess driving difficulty, which might be subject to recall and social desirability bias.

Lastly, this study found that male cataract patients were less likely to self-regulate their driving than females and is consistent with previous research [39, 40]. Retired drivers were also more likely to self-regulate their driving possibly due to the fact they have more flexibility to choose when and where they drive than those who are employed [41].

The major strength of this study was the use of naturalistic objective driving data to examine self-regulation practices and associated changes in objective visual measures throughout the cataract surgery process. Naturalistic data provide valid information and are more accurate than self-reported questionnaires, which are prone to social desirability and recall biases [20]. However, there were several limitations. Participants' naturalistic driving behaviour was only measured for a period of one week meaning this may not be representative of their overall driving patterns, although this time frame is consistent with some previous research $[21,42]$. As well, the study was only able to measure four difficult driving situations and further research should include an extended range of driving situations which have been shown to be challenging among cataract patients such as driving in the rain and parallel parking [11].

\section{Conclusion}

It is well known that driving provides older adults with mobility, independence and enhances quality of life [3]. The current study found that even among a cohort of cataract patients with better vision at baseline, a significant proportion self-regulated or restricted their driving while awaiting surgery. First eye cataract surgery significantly reduced driver self-regulation, with second eye surgery providing further reductions. This study provides a strong rationale for providing timely first and second eye cataract surgery for older drivers with bilateral cataract in order to improve their mobility and independence.

\section{Abbreviations \\ ANOVA: Analysis of variance; Cl: Confidence interval; DHQ: Driving Habits Questionnaire; ETDRS: Early Treatment Diabetic Retinopathy Study; GEE: Generalised Estimating Equation; log: logarithm; logMAR: logarithm of the Minimal Angle of Resolution; MMSE: Mini-Mental State Examination; OBD II: On Board Diagnostic II; OR: Odds ratio; SD: Standard deviation}

\section{Acknowledgements}

The authors thank all participants who volunteered.

\section{Funding}

Financial support was provided by Curtin University, through an International Postgraduate Research Scholarship (\#52423). The funding organisation had no role in the design or conduct of this research. 


\section{Authors' contributions}

SA collected the data, conducted the data analysis, interpretation of data, and drafted the manuscript. LM led the design of the study, conducted the data analysis, interpretation of data, and drafted the manuscript. MF made substantial contributions to the conception and design of the study, analysed and interpreted the data and was involved in drafting and revising the manuscript. KC contributed to the design of the study, analysis of data and drafting and revising of the manuscript. JN contributed to the acquisition of data, interpretation of data and was involved in revising the manuscript critically for important intellectual content. VR made substantial contributions to the acquisition of data and the interpretation of data and revised the manuscript critically for important intellectual content. All authors read, revised and approved the final manuscript

\section{Ethics approval and consent to participate}

Ethics approval was obtained from the Curtin University Human Research Ethics Committee (Curtin University HR 29/2014), the Royal Perth Hospital Human Research Ethics Committee (Royal Perth \#14-033), the South Metropolitan Health Service Human Research Ethics Committee (Fremantle Hospital \#14-033), and the Sir Charles Gairdner Group Human Research Ethics Committee (Sir Charles Gairdner Hospital \#2014-113). Participants provided written informed consent before any data were collected, following the tenets of the Declaration of Helsinki.

\section{Consent for publication}

Not applicable

\section{Competing interests}

The authors declare that they have no competing interests.

\section{Publisher's Note}

Springer Nature remains neutral with regard to jurisdictional claims in published maps and institutional affiliations.

\section{Author details}

'Curtin-Monash Accident Research Centre (C-MARC), Curtin University, GPO BOX U1987, PERTH, WA 6845, Australia. ${ }^{2}$ Eye \& Vision Epidemiology Research (EVER) Group, Perth, WA, Australia. ${ }^{3}$ School of Population and Global Health, The University of Western Australia, Perth, WA, Australia. ${ }^{4}$ Sir Charles Gairdner Hospital, Perth, WA, Australia.

\section{Received: 27 September 2017 Accepted: 6 February 2018}

\section{Published online: 17 February 2018}

\section{References}

1. Holey-Moore G, Creighton $\mathrm{H}$. The future of transport in an ageing society. London: ILC-UK; 2015. http://www.somersetintelligence.org.uk/files/Future_of_ Transport_in_an_Ageing_Society_Jun2015-AgeUK.pdf. Accessed 25 Sept 2017

2. Zeitler E, Buys L. Mobility and out-of-home activities of older people living in suburban environments:'because I'm a driver, I don't have a problem. Ageing Soc. 2015;35:785-808.

3. Gwyther $\mathrm{H}$, Holland $\mathrm{C}$. The effect of age, gender and attitudes on selfregulation in driving. Accid Anal Prev. 2012:45:19-28.

4. Chihuri S, Mielenz TJ, DiMaggio CJ, Betz ME, DiGuiseppi C, Jones VC, Li G. Driving cessation and health outcomes in older adults. J Am Geriatr Soc. 2016:64:332-41.

5. Australian Institute of Health and Welfare. Australia's welfare 2015. Canberra: AlHW; 2015. https://www.aihw.gov.au/getmedia/692fd1d4-0e81-41da-82afbe623a4e00ae/18960-aw15.pdf.aspx?inline=true. Accessed 25 Sept 2017

6. Luiu C, Tight M, Burrow M. The unmet travel needs of the older population: a review of the literature. Transp Rev. 2017;37:488-506.

7. Agramunt S, Meuleners LB, Fraser ML, Morlet N, Chow KC, Ng JQ. Bilateral cataract, crash risk, driving performance, and self-regulation practices among older drivers. J Cataract Refract Surg. 2016;42:788-94.

8. Owsley C, McGwin G. Vision and driving. Vis Res. 2010;50:2348-61.

9. Wood JM, Black AA. Ocular disease and driving. Clin Exp Optom. 2016;99:395-401.

10. Owsley C, Stalvey B, Wells J, Sloane ME. Older drivers and cataract: driving habits and crash risk. J Gerontol A Biol Sci Med Sci. 1999;54:M203-M11.

11. Fraser ML, Meuleners $\mathrm{LB}, \mathrm{Ng} J \mathrm{Q}$, Morlet N. Driver self-regulation and depressive symptoms in cataract patients awaiting surgery: a cross-sectional study. BMC Ophthalmol. 2013;13:45
12. Baldock MR, Mathias JL, McLean AJ, Berndt A. Self-regulation of driving and its relationship to driving ability among older adults. Accid Anal Prev. 2006;38:1038-45.

13. Molnar $L$, Eby DW. The relationship between self-regulation and drivingrelated abilities in older drivers: an exploratory study. Traffic Inj Prev. 2008:9:314-9.

14. Lundström M, Barry P, Henry Y, Rosen P, Stenevi U. Evidence-based guidelines for cataract surgery: guidelines based on data in the European registry of quality outcomes for cataract and refractive surgery database. J Cataract Refract Surg. 2012;38:1086-93.

15. Freeman EE, Munoz B, Turano KA, West $\mathrm{S}$. Measures of visual function and their association with driving modification in older adults. Invest Ophthalmol Vis Sci. 2006:47:514-20.

16. Keay L, Munoz B, Turano KA, Hassan SE, Munro CA, Duncan DD, Baldwin K, Jasti S, Gower EW, West SK. Visual and cognitive deficits predict stopping or restricting driving: the Salisbury eye evaluation driving study (SEEDS). Invest Ophthalmol Vis Sci. 2009:50:107-13.

17. McGwin G, Scilley K, Brown J, Owsley C. Impact of cataract surgery on selfreported visual difficulties: comparison with a no-surgery reference group. J Cataract Refract Surg. 2003;29:941-8.

18. Molnar LJ, Charlton JL, Eby DW, Langford J, Koppel S, Kolenic GE, Marshall S. Factors affecting self-regulatory driving practices among older adults. Traffic Inj Prev. 2014;15:262-72.

19. Sandlin D, McGwin G, Owsley C. Association between vision impairment and driving exposure in older adults aged 70 years and over: a populationbased examination. Acta Ophthalmol. 2014;92:e207-e12.

20. Huebner KD, Porter MM, Marshall SC. Validation of an electronic device for measuring driving exposure. Traffic Inj Prev. 2006;7(1):76-80.

21. Blanchard RA, Myers AM, Porter MM. Correspondence between selfreported and objective measures of driving exposure and patterns in older drivers. Accid Anal Prev. 2010;42:523-9.

22. Porter MM, Smith GA, Cull AW, Myers AM, Bédard M, Gélinas I, Mazer BL, Marshall SC, Naglie G, Rapoport MJ, Tuokko HA. Older driver estimates of driving exposure compared to in-vehicle data in the Candrive II study. Traffic Inj Prev. 2015;16:24-7.

23. Meuleners LB, Agramunt S, Ng JQ Morlet N, Keay L, McCluskey P, Young M. The cataract extraction and driving ability research study protocol: characterisation of deficits in driving performance and self-regulation among older drivers with bilateral cataract. Inj Prev. 2015;21:424-9.

24. Fraser ML, Meuleners $L B$, Lee AH, Ng JQ, Morlet N. Which visual measures affect change in driving difficulty after first eye cataract surgery? Accid Anal Prev. 2013;58:10-4.

25. Folstein MF, Folstein SE, McHugh PR. "Mini-mental state": a practical method for grading the cognitive state of patients for the clinician. J Psychiatr Res. 1975;12:189-98

26. Ferris FL, Kassoff A, Bresnick GH, Bailey I. New visual acuity charts for clinical research. Am J Ophthalmol. 1982:94:91-6.

27. Dougherty BE, Flom RE, Bullimore MA. An evaluation of the Mars letter contrast sensitivity test. Optom Vis Sci. 2005;82:970-5.

28. Australian Government. Bureau of Meteorology. http://www.bom.gov.au. Accessed 27 Sept 2017

29. Mainroads. Traffic Management at Roadworks on State Roads. Policy and application guidelines. Mainroads, Western Australia. 2015. https://www. mainroads.wa.gov.au/Documents/Traffic\%20Management\%20at\%20Road works\%20on\%20State\%20Roads\%20Policy\%20and\%20Application\%20 Guidelines\%20-\%20WEB\%20version\%20August\%202015.RCN-D15\%5E2 3486558.PDF. Accessed 25 Sept 2017.

30. Zeger SL, Liang KY. Longitudinal data analysis for discrete and continuous outcomes. Biometrics. 1986:(1):121-30.

31. Mönestam E, Wachtmeister L. Impact of cataract surgery on car driving: a population based study in Sweden. Br J Ophthalmol. 1997;81:16-22.

32. Mönestam E, Lundquist B, Wachtmeister L. Visual function and car driving: longitudinal results 5 years after cataract surgery in a population. $\mathrm{Br} J$ Ophthalmol. 2005;89:459-63.

33. Owsley C, McGwin G, Sloane M, Wells J, Stalvey BT, Gauthreaux S. Impact of cataract surgery on motor vehicle crash involvement by older adults. JAMA. 2002;288:841-9.

34. Wood JM, Bilateral CTP. Cataract surgery and driving performance. Br J Ophthalmol. 2006;90:1277-80.

35. Huisingh C, Levitan EB, Irvin MR, MacLennan P, Wadley V, Owsley C. Visual sensory and visual-cognitive function and rate of crash and near-crash 
involvement among older drivers using naturalistic driving data. Invest Ophthalmol Vis Sci. 2017;58:2959-67.

36. Comas M, Castells X, Acosta ER, Tuni J. Impact of differences between eyes on binocular measures of vision in patients with cataracts. Eye. 2007;21:702-7.

37. KG TO, Meuleners LB, Fraser ML, Van Do D, Van Duong D, Huynh VA, QG TO, Phi TD, Tran HH, Do Nguyen N. The impact of cataract surgery on vision-related quality of life for bilateral cataract patients in ho chi Minh City, Vietnam: a prospective study. Health Qual Life Outcomes. 2014;12:16.

38. Fonda SJ, Wallace RB, Herzog AR. Changes In driving patterns and worsening depressive symptoms among older adults. J Gerontol B Psychol Sci Soc Sci. 2001;56:S343-S51.

39. Conlon EG, Rahaley N, Davis J. The influence of age-related health difficulties and attitudes toward driving on driving self-regulation in the baby boomer and older adult generations. Accid Anal Prev. 2017;102:12-22.

40. Wong IY, Smith SS, Sullivan KA. Psychosocial factors significantly predict driving self-regulation in Australian older adults. Australas J Ageing. 2016:35:133-8.

41. Molnar LJ, Eby DW, Charlton JL, Langford J, Koppel S, Marshall S, Man-SonHing M. Driving avoidance by older adults: is it always self-regulation? Accid Anal Prev. 2013;57:96-104.

42. Thompson JP, Baldock MR, Mathias JL, Wundersitz LN. A comparison of reported driving self-regulation by older adults and GPS-based measurements of their actual driving exposure. Road Transp Res. 2016;25:16-27.

\section{Submit your next manuscript to BioMed Central and we will help you at every step:}

- We accept pre-submission inquiries

- Our selector tool helps you to find the most relevant journal

- We provide round the clock customer support

- Convenient online submission

- Thorough peer review

- Inclusion in PubMed and all major indexing services

- Maximum visibility for your research

Submit your manuscript at www.biomedcentral.com/submit 